\title{
The role of mast cells in pediatric gastrointestinal disease
}

\author{
Naseem Ravanbakhsha, Anil Kesavan ${ }^{b}$ \\ Rush University Children's Hospital, Chicago, IL, USA
}

\section{Abstract}

\section{Mast cell (MC) physiology}

MCs are tissue-resident granulocytes that form an integral part of the allergic response and also play a role in immune tolerance, innate immunity, angiogenesis, and wound healing [1]. MCs are found throughout the body and are common at mucosal surfaces (skin, respiratory tract, and gastrointestinal [GI] tract) that interface with the external environment, often in proximity to blood vessels and nerves, where they form host barriers [2-4]. Their action against pathogens is important to innate immunity; they are important gatekeepers for fighting infectious organisms in portals of entry [5].

MCs do not represent a homogenous population of cells but exhibit significant functional and phenotypic heterogeneity

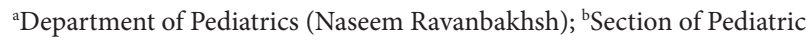
Gastroenterology (Anil Kesavan), Rush University Children's Hospital, Chicago, IL, USA

Conflict of Interest: None

Correspondence to: Anil Kesavan, MD, Rush University Children's Hospital, Professional Building, 1725 W Harrison St, Suite 710, Chicago, IL 60612, USA, e-mail: anil_a_kesavan@rush.edu

Received 12 September 2018; accepted 2 April 2019; published online 22 April 2019

DOI: https://doi.org/10.20524/aog.2019.0378 depending on the microenvironment in which they mature [4-6]. This heterogeneity manifests as differences in morphology, biological functions, responsiveness to growth factors, and sensitivity to drugs and secretagogues [5]. Human MCs are classified by their content of serine proteases: tryptase only MC $\left(\mathrm{MC}^{\mathrm{T}}\right)$, chymase only $\left(\mathrm{MC}^{\mathrm{C}}\right)$, or both tryptase and chymase positive $\mathrm{MC}\left(\mathrm{MC}^{\mathrm{TC}}\right)$ [5]. Human $\mathrm{MC}^{\mathrm{T}}$ are located predominately in mucosal tissues, such as the intestine and respiratory tract, whereas human $\mathrm{MC}^{\mathrm{TC}}$ are mainly found in connective tissues, such as the skin, but may also be found in the submucosa and muscularis propria of the intestinal tract [7].

MCs contain mediators active in both inflammatory and immunological reactions [8]. MCs are capable of reacting within minutes or hours to physical, biological, and chemical stimuli with either local or systemic effects [6]. These cells are activated by cross-linking of cell-surface IgE to antigens, as well as through non-IgE dependent stimulation (complement activation products, microbial components, medications, tissue trauma) $[9,10]$. Activation results in the release of a wide variety of bioactive mediators into adjacent tissues, where they exert physiological responses directly or indirectly via activation of other effector cells [11].

MCs release a number of mediators upon stimulation that differ in their potency and biological activities. The spectrum of mediators and cytokines produced and released by heterogeneous MCs differs depending on the MC subpopulation 
and the type of stimulation [6,11]. MCs isolated from human intestine express mRNA for a variety of pro-inflammatory cytokines (tumor necrosis factor [TNF]- $\alpha$, interleukin [IL]-1 $\beta$, IL-6, IL-8, IL-16, and IL-18) [12].

Mediators are categorized into 2 groups: preformed and newly synthesized. Preformed mediators are stored in granules and include biogenic amines (histamine), proteoglycans, neutral proteases, and cytokines-a combination of over 50 active factors that help facilitate arteriole vasodilation and vascular permeability $[11,13,14]$ (Table 1). Newly synthesized mediators include arachidonic acid metabolites (prostaglandin $\mathrm{D} 2$, leukotriene $\mathrm{B}_{4}$, platelet-activating factor, leukotriene $\mathrm{C}_{4}$ ) and cytokines; these mediators need RNA transcription and are released within minutes to hours upon MC stimulation $[1,11,14,15]$ (Table 2).

MCs are best known for their prompt secretion of granules (degranulation) that contain large stores of preformed mediators [4]. Preformed mediator release following MC stimulation can result in the release of large quantities of stored histamine within 15-90 sec [4]. This release enables both rapid anaphylactic reactions and allergic responses. It also initiates recruitment of leukocytes to sites of pathogen invasion, activation of innate immune processes and development of inflammatory responses [4]. Long-term responses associated with granule-derived mediators include wound healing and tissue remodeling processes through communication with other cells (fibroblast proliferation and extracellular matrix production) [4].

\section{MCs and the GI tract}

From birth and steadily through childhood there is an incremental rise in $\mathrm{MC}$ density that eventually reverses with

Table 1 Preformed mast cell mediators

\begin{tabular}{llll}
\hline $\begin{array}{l}\text { Biogenic } \\
\text { amines }\end{array}$ & $\begin{array}{l}\text { Neutral } \\
\text { proteases }\end{array}$ & Proteoglycans & $\begin{array}{l}\text { Lysosomal } \\
\text { enzymes }\end{array}$ \\
\hline Histamine & $\begin{array}{l}\text { Tryptases } \\
\text { (tryptase- } \alpha, \beta \text { I, } \\
\beta I I, \beta I I I, \gamma, \delta)\end{array}$ & Heparin & $\beta$-glucuronidase \\
Serotonin & Chymase-1 & $\begin{array}{l}\text { Chondroitin } \\
\text { sulfates }\end{array}$ & $\beta$-hexosaminidase \\
& $\begin{array}{l}\text { Cathepsin G } \\
\text { Granzyme B }\end{array}$ & Serglycin & Arylsulfatase \\
\hline Moon TC et al $[4]$ & & & \\
\hline
\end{tabular}

aging [8]. The number of MCs varies throughout the body, depending on the location and immunologic function of a particular organ [16]. The highest number of progenitor cells was found in the GI tract $[16,17]$. Such a location may be optimal given the role that MCs play in the host's defense against bacterial, viral, and parasitic infections. MCs are also thought to regulate a number of physiological functions in the intestine, including epithelial function (water and electrolyte secretion, tight junction/epithelial barrier integrity), endothelial function (blood flow, vessel contraction, endothelial permeability, coagulation/fibrinolysis), cell influx into tissue (neutrophils, eosinophils, lymphocytes), neuroenteric function (intestinal peristalsis, pain mediation), and tissue transformation (wound healing, fibrosis) [17] (Table 3).

Most human tissues have mixed populations of MC types. In the human intestinal mucosa $>80 \%$ of $\mathrm{MCs}$ are $\mathrm{MC}^{\mathrm{T}}$ and $20 \% \mathrm{MC}^{\mathrm{TC}}$, while the opposite applies to the intestinal submucosa [5].MCs are present in all layers of the GI tract, but are located predominately in the lamina propria and the submucosal layer [11]. MCs comprise about 2-5\% of mononuclear cells in the lamina propria and $1 \%$ of all cells found in the intestinal submucosa [16,18]. Typically, MCs do not show clustering (aggregate of 5 or more MCs) and are not present within the surface epithelium [19].

The number and distribution of MCs in the pediatric GI tract is not well defined. An average of 13 cells per highpower field (hpf) is seen in the duodenum and colon $[16,18]$. The largest number of MCs exists in the descending colon $(17 \pm 7 \mathrm{MCs} / \mathrm{hpf})$ and the lowest in the rectosigmoid (14 $\pm 6 \mathrm{MCs} / \mathrm{hpf})$ [19].

MCs are located in proximity to blood vessels and nerve fibers, which makes them an ideal candidate for modulating neural activity and nociception [20]. Approximately 70\% of intestinal mucosal MCs are in direct contact with nerve fibers, while another $20 \%$ are within $2 \mu \mathrm{m}$. Given such proximity, MCs are thought to play a role in visceral sensitivity [16]. MCs can interact with the nervous system bidirectionally; MC mediators such as tryptase and histamine lead to the release of neuropeptides, such as substance P (SP) and calcitoningene related peptide, from the proximal nerve endings and SP can subsequently further activate MCs [20]. The motor neuron response, as a result of MC degranulation, can lead to hypersecretion in the GI tract, resulting in diarrhea, abdominal pain, and cramping. Other mediators released by MC degranulation can also sensitize nociceptors in the large intestine. In animal models, this mechanism was shown to reduce the threshold for pain with rectal distension-responses

Table 2 Newly synthesized mast cell mediators

\begin{tabular}{llll}
\hline Eicosanoids (Arachidonic acid metabolites) & & Cytokines \\
\hline Prostaglandins $\left(\mathrm{PGD}_{2}\right)$ & $\begin{array}{l}\text { Cysteinyl } \\
\text { Leukotrienes }\left(\mathrm{LTC}_{4}, \mathrm{LTB}_{4}\right)\end{array}$ & $\begin{array}{l}\text { Platelet-activating } \\
\text { factor }\end{array}$ & $\begin{array}{l}\text { IL-1-6, IL-8, IL-16, IL-18, TNF- } \alpha \text {, TGF- } \beta, \text { bFGF, MCP-1, } \\
\text { MIP-1 } \alpha, \text { MIP-1 } \beta \text {, VEGF, GM-CSF }\end{array}$ \\
$\begin{array}{l}\text { Yu LC et al [11], } \\
\text { Bischoff SC et al [14] }\end{array}$ & & \\
\hline
\end{tabular}

IL, interleukin; TNF, tumor necrosis factor; TGF, transforming growth factor; bFGF, basic fibroblast growth factor; MCP, monocyte chemoattractant protein; MIP, macrophage inflammatory protein; VEGF, vascular endothelial growth factor; GM-CSF, granulocyte-macrophage colony-stimulating factor 
Table 3 Physiologic role of mast cells in the intestine

\begin{tabular}{|c|c|c|c|c|c|}
\hline Epithelial function & Endothelial function & $\begin{array}{l}\text { Cell influx } \\
\text { into tissue }\end{array}$ & $\begin{array}{l}\text { Neuroenteric } \\
\text { function }\end{array}$ & $\begin{array}{l}\text { Tissue } \\
\text { transformation }\end{array}$ & $\begin{array}{l}\text { Host } \\
\text { defense }\end{array}$ \\
\hline $\begin{array}{l}\text {-water and electrolyte } \\
\text { secretion } \\
\text {-tight junction/epithelial } \\
\text { barrier integrity }\end{array}$ & $\begin{array}{l}\text {-blood flow } \\
\text {-vessel contraction } \\
\text {-endothelial } \\
\text { permeability-coagulation/fibrinolysis }\end{array}$ & $\begin{array}{l}\text {-neutrophils } \\
\text {-eosinophils } \\
\text {-lymphocytes }\end{array}$ & $\begin{array}{l}\text {-peristalsis } \\
\text {-pain mediation }\end{array}$ & $\begin{array}{l}\text {-wound healing } \\
\text {-fibrosis }\end{array}$ & $\begin{array}{l}\text {-bacteria } \\
\text {-viruses } \\
\text {-parasites }\end{array}$ \\
\hline
\end{tabular}

Bischoff SC et al [17]

that can both be prevented and controlled with MC stabilizing drugs like cromolyn [16].

MCs are also responsive to both acute and chronic stress [16,17]. Stress can cause increased release of MC mediators (histamine and tryptase) in the proximal intestine in healthy controls and to a larger extent in those with an MC-associated disease (such as food allergy) [17]. There is additional evidence that stress affects intestinal barrier function. This pathway appears to be mediated by the release of corticotropin-releasing hormone, with subsequent activation of mucosal MCs [21].

While beneficial in fighting off pathogens and initiating protective measures, MCs in the GI tract are also implicated in pathologic phenomena under certain circumstances. MCs may transition from a protective, homeostatic role to one that is detrimental and proinflammatory, leading to the development of disease [13]. MC activation can lead to inflammation, which may affect motility, mucosal permeability, intestinal barrier function, and visceral sensitivity [16,17]. By increasing mucosal permeability, MCs can contribute to an ongoing inflammatory process, independently of whether the process is triggered by a harmful microbe or allergen [17]. Hence, MCs have been implicated in the underlying pathophysiology of a number of GI disorders that affect children.

\section{MCs and diagnostic evaluation}

The documentation of MC mediator release, at baseline as well as during symptomatic periods, is suggestive of the presence of MC involvement in the pathophysiology of clinical conditions. Pediatric data, however, are limited and the presence of these biomarkers in children must be interpreted with caution. Tryptase is the preferred biomarker for a diagnosis of MC-activation syndrome (MCAS) [22]. Tryptase can be used to reflect MC burden in the body. Consecutive measurements of serum tryptase were found to be helpful when assessing and predicting the clinical course of MCAS. The timing of sample collection and the severity of the clinical event should also be considered when interpreting tryptase results. For example, serum tryptase peaks 15-60 min after an anaphylactic event and declines with a half-life of about $2 \mathrm{~h}$ [23]. Other biomarkers, such as 24-h urinary histamine metabolites, 24-h urinary prostaglandin D2 or its metabolite $11 \beta$-prostaglandinF2 $\alpha$, can be helpful, but meaningful elevation cutoffs have not been established $[9,24]$.

\section{Eosinophilic esophagitis (EoE)}

EoE is a chronic, immune-mediated disease characterized by eosinophil-predominant inflammation isolated to the esophagus (peak count of $\geq 15$ eosinophils per hpf) $[25,26]$. EoE is strongly linked to atopy and is often found in association with asthma, allergic rhinitis, eczema, food and aeroallergen hypersensitivity. A non-IgE-mediated mechanism, characterized by a Th2-predominant immune response, plays an important role in the development of disease [26]. Eosinophilic recruitment occurs via mediators like IL-5 and the eotaxin family of chemokines. Eotaxin-3 gene (encoded by CCL26) has been found to be abundantly expressed in the esophagus of EoE patients; expression correlates with disease activity [26,27]. Once activated, eosinophils then modulate various aspects of the immune response and can damage the surrounding tissue [26,27].

Recent studies suggest that MCs may be involved in the development and pathogenesis of EoE; several possible mechanisms have been proposed [7]. MCs produce cytokines (IL-4, IL-5, IL-13, granulocyte-macrophage colony-stimulating factor, eotaxin-1) that activate eosinophils. MCs also promote eosinophil recruitment by synthesizing and releasing eosinophil-selective chemokines and leukotrienes [7]. An increased number of MCs (20-fold increase found in the mucosal layer of the esophagus) has been noted in esophageal biopsies from patients with EoE $[7,18]$. MC density correlates with the severity of esophageal eosinophilia and the number of MCs decreases after treatment [7]. In addition, these MCs undergo substantial degranulation in EoE compared with healthy controls [18]. Genes associated with MC recruitment are upregulated in EoE and produce inflammatory mediators, implicated both in the migration of inflammatory cells as well as fibrosis generation [28].

MCs may promote not only inflammation but also fibrosis in EoE, by secreting factors such as transforming growth factor- $\beta$, a proinflammatory cytokine that induces smooth muscle contractility contributing to esophageal dysfunction, and tryptase, which promotes proliferation and collagen secretion $[27,29]$.

These findings suggest that MCs are actively involved in the development of EoE [7]. The effect of MC mediator production in EoE may enhance inflammation (through recruitment and activation of eosinophils), alter esophageal motility, and promote stricture formation [7]. 


\section{Functional dyspepsia (FD)}

FD, like other functional GI disorders, is best understood through a biopsychosocial model that incorporates the interaction between physiological factors (inflammation, visceral hypersensitivity, motility disturbances), psychological factors (depression, anxiety, somatization), and social factors (interaction with peers and family) [30]. There is evidence to implicate MCs as a key physiological factor in the pathogenesis of pediatric FD. Increased antral MC density is associated with slower gastric emptying and pre-prandial dysrhythmia in children with FD [30,31]. Moderate to extensive degranulation of MCs is seen in the antrum of pediatric FD patients [32]. Antral MC density also correlates with anxiety scores in children with FD [33]. A correlation has also been noted between gastric MC density and symptoms of postprandial fullness and early satiety commonly seen in FD [32].

The above data suggest that there is an interaction between antral inflammation, gastric electromechanical dysfunction, and development of symptoms in pediatric FD [32]. However, the increased small bowel permeability that has been demonstrated in subsets of patients with irritable bowel syndrome (IBS) is not seen in children with FD, even in the presence of elevated MC density [21]. A study by Yeom et al found that headache associated with dyspeptic symptoms in pediatric FD patients is associated with gastric mucosal MC density, suggesting that MCs may functionally link the brain and the gut in pediatric FD [34].

MCs appear to play a key role in the pathogenesis of FD, modulating both gastric motility and gastric visceral hypersensitivity. This may help us to understand why certain antihistamines, such as cyproheptadine, provide symptom relief in patients with FD. Future studies should include the use of mast-cell stabilizing medications in the treatment of FD.

\section{Celiac disease}

Celiac disease is characterized by immune-mediated mucosal damage that occurs as a result of both an adaptive and an innate response to the ingestion of dietary gliadin. A recent study conducted by Frossi et al suggests that MCs are central to the inflammatory process present in celiac disease [35]. Intestinal biopsy specimens of patients with celiac disease demonstrate a correlation between MC density and disease severity. Additionally, it was found that gliadin fragments bind to MCs, thereby activating these cells, inducing degranulation and providing a mechanism through which MCs have a direct role in both the onset and progression of disease [35].

While there is little in the current literature regarding the role of MCs in the pathogenesis of celiac disease, an increased awareness of how these cells promote and exacerbate inflammation may provide new treatment modalities in the future.
IBS is a functional disorder with a multifactorial pathogenesis, including visceral hypersensitivity, increased intestinal permeability, intestinal dysbiosis, food intolerance, psychological stress and brain-gut axis dysfunction [36]. It has been suggested that low grade immune activation and neuroimmune interactions within the colonic mucosa play an important role in the development of sensorimotor dysfunction and symptoms in IBS patients [37]. A number of studies have demonstrated an increased density of MCs in the duodenum, jejunum, terminal ileum and colon of adult IBS patients [37-40]. Additional studies have reported the proximity of MCs to enteric nerves in the colonic mucosa, indicating a key role in the development of visceral hypersensitivity that is central to the pathogenesis of IBS $[36,39,41]$. An increased number of degranulated MCs seen by electron microscopy in the colon of IBS patients has also been noted [36,39]. MC degranulation increases the excitability of vagal, splanchnic, and mesenteric afferents, contributing to nociceptive processes associated with visceral pain [36].

Additional studies have demonstrated a connection between a patient's psychological state and an increased colonic mast-cell concentration. IBS patients with high fatigue and depression scores, as assessed by the Fatigue Impact Scale and Beck Depression Inventory, respectively, were specifically found to have a greater number of MCs in intestinal biopsies [42].

These findings have also been recognized in pediatric IBS patients. An increased number of MCs has been noted in the terminal ileum and colon of pediatric patients with IBS [37]. Furthermore, MC density is related to the intensity and frequency of abdominal pain in these patients [37]. Other studies have suggested increased MC activity in pediatric IBS patients. An increased amount of nerve growth factor (NGF), which may play a role in the development of visceral hypersensitivity and is produced by MCs, has been reported in the rectal mucosa of pediatric patients with diarrhea-predominant IBS [43].

These studies demonstrate a greater density and activity of MCs in the small and large intestine of patients with IBS compared with healthy controls. The role of MCs in the development of visceral hypersensitivity is important. IBS is a challenging disorder to treat; better understanding of how MCs are involved the pathogenesis of the disease may lead to more effective long-standing treatment options.

\section{Inflammatory bowel disease (IBD)}

IBD is chronic inflammatory disease attributed to a complex interaction between genetic and environmental factors leading to an aberrant immune response to intestinal microbiota [44]. Increased numbers of MCs in inflamed segments of bowel compared with the non-inflamed segments of bowel have been seen in patients with ulcerative colitis and Crohn's disease [45]. Increased levels of MC mediators such as histamine, prostaglandin D2, and leukotrienes have also been noted in 
patients with IBD [46]. Studies demonstrate that activated MCs in vitro release TNF- $\alpha$, shown to play a critical role in the pathogenesis of IBD. Approximately half of the lamina propria cells producing TNF- $a$ were derived from MCs [47].

Despite this current understanding, the exact mechanism by which MC mediators participate in IBD is still unclear. One proposed mechanism suggests that MC dysfunction in regulating epithelial permeability may be important in the development of disease [13]. Tight junctions must be maintained to prevent the permeation of destructive pathogens and allergens into the mucosa, where they can further provoke MC-dependent inflammation. Disturbances in the epithelium can initiate or worsen inflammation in IBD [13]. This has been demonstrated in an animal model, where rats deficient in MCs (or MC mediator chymase) had lower intestinal permeability compared with wild-type mice, further supporting their role in epithelial membrane homeostasis in the intestinal tract [48].

Furthermore, patients with IBD commonly report IBSlike symptoms, such as abdominal pain and diarrhea, during remissive phases. Such findings are relevant in this setting, suggesting that as inflammation resolves, a group of mucosa and submucosal MCs remain active, contributing to GI symptoms even after the resolution of an IBD flare [13]. A greater number of MCs in close proximity to nerve endings was found in patients with ulcerative colitis, probably contributing to IBSlike symptoms during clinical remission of the underlying IBD [49].

While it has already been established that stress can precede IBD flares and induce changes in the epithelial barrier, studies are now supporting mast-cell involvement in stress-induced changes in IBD [50]. Santos et al conducted a study that analyzed MC-deficient and sufficient rats in times of stress. Both groups were subjected to 5 days of water deprivation, where rats were able to see but not drink water for several days. Results demonstrated that the colons of stressed, MC-sufficient rats had increased numbers of MCs, with evidence of MC activation for an entire 3-day period after the initial stressor [50].

MCs are also thought to play a role in the development of strictures and fistulae, 2 irreversible complications of chronic intestinal inflammation in IBD, related to poor wound healing [51]. MCs and their mediators play important roles in inflammation, proliferation, and remodeling of wound healing [51]. An ongoing presence of MCs for up to 20 days after an IBD exacerbation, even when other inflammatory cells were normalized, has been noted [52]. MCs also accumulate at the site of injury, releasing mediators and attracting other immune cells. They are capable of inducing nearby cells to increase their expression of biologically active factors important to the formation of strictures in Crohn's disease [13].

IBD is due to an aberrant immune response to commensal flora; MCs appear to be involved in this process. Increased MC density has been noted in inflamed areas of intestine in patients with IBD. Activated MCs release TNF- $\alpha$ and other mediators involved in the propagation of intestinal inflammation, increased intestinal permeability, and the development of fistulae and strictures.

\section{Appendicitis}

The hallmark of acute appendicitis is neutrophilic predominance and infiltration in the mucosa and wall of the appendix. However, about $15-25 \%$ of appendices do not display neutrophilic infiltration and are therefore deemed histologically negative appendicitis [53]. In this scenario, MCs are thought to play a role. Yang et al studied 50 pediatric appendectomy cases and found that 30 of them were histologically negative. This study demonstrated the greatest MC density in the mucosa of both normal and histologically negative appendices. MC density, however, was elevated in all 4 layers of the intestinal tract in histologically negative appendices compared with normal controls, suggesting the importance of MCs in the pathogenesis of pediatric histologically negative appendicitis [53]. MC accumulation was therefore thought to provoke appendicitis-like pain in patients with histologically negative appendices via the release of cytokines, especially in close proximity to enteric nerve fibers [53]. These findings have also been reported in adults with histologically negative appendicitis $[54,55]$.

In addition, MCs may also play a role in the pathophysiology of histologically evident appendicitis. Karakus et al examined the distribution of multiple cell types, including eosinophils and MCs, in children with normal and inflamed appendices. They found a statistically significant increase in the number of MCs in the appendicitis group compared with the control group, which correlated with the degree of inflammation. Such findings suggest that MCs and their metabolites are important in the development of appendicitis in children [56].

MCs appear to play a role in both histologically evident appendicitis as well as histologically negative appendicitis. Histologically negative appendicitis is mediated through MC activation of enteric nerve fibers, resulting in pain, while MC density is increased in histologically evident appendicitis, suggesting a role in the inflammatory process.

\section{Hirschsprung's disease (HD) and intestinal neuronal dysplasia (IND)}

$\mathrm{HD}$ is a rare congenital disorder that is due to an absence of ganglia in the submucosal and intramuscular plexus of the GI tract [57-59]. Hypertrophic nerve trunks and increased numbers of adrenergic and cholinergic nerve (AchE-positive) fibers are seen in the aganglionic bowel segment $[57,58,60]$. Children below 6 months demonstrate hypertrophied nerve trunks and fibers only in the muscular mucosa and submucosa [59]. In children over 6 months there are abundant nerve fibers in all 3 layers of the mucosa [59]. Despite extensive research, the pathogenesis of the disease is not fully understood. There have been reports suggesting that MCs may play a role in the development of HD [58,60-62].

MCs have been observed in direct contact with nerve fibers, suggesting that they are essential for nerve growth and repair [58,61]. They synthesize, store, and release 
NGF, which supports the development and maintenance of nerve fibers [58,61]. Increased numbers of MCs have been reported in the aganglionic segment of the colon in patients with HD [58,60-62]. A transmural distribution was found in HD patients, with increases of MCs in all layers of the aganglionic segment $[58,60,62]$. MCs were also found to be in contact with hypertrophic nerve trunks in aganglionic segments in $\mathrm{HD}$, suggesting that MCs may contribute to the development of hypertrophic nerve trunks through the release of NGF $[58,60,61]$. While the exact role of MCs in HD is not known, these findings suggest that MCs may be involved in the pathogenesis of the disease.

First described by Meier-Ruge in 1971, IND represents a range of neural-crest malformations [60]. Although IND is not clearly defined, suggested morphologic features include hyperplasia of enteric ganglia, giant and ectopic ganglia, and increased activity of acetylcholinergic nerve fibers [58,60]. Large numbers of MCs have been found in all layers of IND segments compared with non-IND segments and controls $[58,60]$. This suggests that MCs may be responsible for the development of giant ganglia. While depletion of mucin is seen in aganglionic segments in HD patients, this finding is not found in IND, indicating that innervation anomalies in IND do not affect colonic epithelial differentiation as in HD [60].

The pathogenesis of HD and IND has not been fully elucidated. The extensive presence of MCs in the intestinal tissue of both these disease entities suggests that these cells may contribute to the development of disease. MCs are involved in the development and growth of nerve fibers. In this context, aberrant function of MCs may lead to disease.

\section{Food protein-induced proctocolitis (FPIES)}

FPIES is a severe non-IgE-mediated food allergy that affects infants and young children [63]. Recent data suggest involvement of MCs in addition to both T cells and neutrophils. Markedly increased MCs (50 per hpf) have been found in the rectum during the acute phase of FPIES [64]. Elevated baseline serum tryptase levels have been reported in pediatric patients with active FPIES, suggesting that MC activation is part of the disease [65].

\section{MCAS}

MCAS comprise a heterogeneous group of conditions associated with recurrent signs and symptoms of MC mediator release, most notably histamine $[1,23,66]$. Symptoms depend on the affected organ and include skin (flushing, pruritus, urticaria, angioedema, dermatographism), GI (gastroesophageal reflux disorder, nausea, vomiting, diarrhea, and abdominal cramping), cardiovascular (hypotension, syncope, near syncope, tachycardia), respiratory (wheezing, throat swelling), naso-ocular (nasal congestion, conjunctival injection, nasal pruritus), anaphylaxis, and neurologic (headaches, poor concentration, memory issues, brain fog) manifestations $[67,68]$.

MCAS can be classified into 3 distinct categories: primary (clonal), secondary (reactive), and idiopathic [1,23,66,67]. Primary MCAS are associated with KIT D816V or other KIT exon 17 mutations and are characterized by abnormal qualitative or quantitative production of MCs $[9,69]$. Primary MCAS includes mastocytosis and monoclonal MC activation syndrome; diagnosis is based on objective pathologic findings, as stated in the World Health Organization (WHO) diagnostic criteria $[23,69]$. The WHO classification divides mastocytosis into 7 categories, each with distinct clinicopathologic and prognostic features $[9,69,70]$. Cutaneous mastocytosis (CM) is the most common form in children, accounting for over $90 \%$ of pediatric mastocytosis cases [9,69-71]. Pediatric CM is limited to the skin, with no bone marrow or other organ involvement. Systemic mastocytosis (SM), where multiple organ systems are affected (with bone marrow involvement), is rare in children [69]. Virtually all patients with pediatric SM have skin involvement. Organomegaly in conjunction with evidence of MC mediator release is highly suggestive of SM in pediatric patients [72].

Secondary MCAS are more prevalent than primary and idiopathic MCAS and occur in IgE-dependent allergies, chronic inflammatory diseases, neoplastic disorders, physical urticarias, and chronic autoimmune urticaria $[23,67]$. MCs are produced normally and are generally present in normal numbers in tissues or can be increased in response to an underlying inflammatory process (reactive MC hyperplasia) [69].

Idiopathic MCAS has no identifiable cause; hypotheses concerning the underlying etiology include an intrinsic MC defect, an unidentified endogenous or environmental stimulus, or both, resulting in a hyperactive MC phenotype [23,73].

No consensus definition for idiopathic MCAS has been established, but proposed diagnostic criteria include: 1) episodic multisystem symptoms consistent with MC mediator release; 2) increased levels of MC mediators above baseline during symptomatic periods; 3) clinical improvement with $\mathrm{H}_{1}$ and $\mathrm{H}_{2}$-receptor antagonists, anti-leukotriene medications, or MC stabilizing agents; and 4) no evidence of a primary or secondary disorder of MC activation [24,67,69]. While this condition has predominately been described in adults, pediatric manifestations of idiopathic MCAS are not well recognized.

Pediatric MCAS includes primary, secondary, and idiopathic forms. Primary (clonal) MCAS is extremely rare in children and if present typically takes the form of CM, imited to the skin. Secondary MCAS is more prevalent in children and occurs secondarily to a variety of allergic and inflammatory conditions. Idiopathic MCAS is poorly understood and has not been clearly defined in the pediatric population.

\section{Concluding remarks}

MCs are active in both inflammatory and immunologic reactions, through the release of preformed or newly synthesized mediators in response to various stimuli. These cells 
have an important role in a multitude of physiologic processes. It is clear that MCs play an active role in the pathogenesis of a variety of pediatric GI disorders. A better understanding of how these cells contribute to pediatric GI disease will allow development of new therapeutic modalities in the future.

\section{References}

1. Cookson H, Grattan C. An update on mast cell disorders. Clin Med (Lond) 2016;16:580-583.

2. Dawicki W, Marshall JS. New and emerging roles for mast cells in host defence. Curr Opin Immunol 2007;19:31-38.

3. Heib V, Becker M, Taube C, Stassen M. Advances in the understanding of mast cell function. Br J Haematol 2008;142: 683-694.

4. Moon TC, Befus AD, Kulka M. Mast cell mediators: their differential release and the secretory pathways involved. Front Immunol 2014;5:569.

5. Vliagoftis H, Befus AD. Rapidly changing perspectives about mast cells at mucosal surfaces. Immunol Rev 2005;206:190-203.

6. Mekori YA, Metcalfe DD. Mast cells in innate immunity. Immunol Rev 2000;173:131-140.

7. Wershil BK. Exploring the role of mast cells in eosinophilic esophagitis. Immunol Allergy Clin North Am 2009;29:189-195.

8. Dollberg, L, Gurevitz M, Freier S. Gastrointestinal mast cells in health, and in coeliac disease and other conditions. Arch Dis Child 1980;55:702-705.

9. Akin C. Mast cell activation disorders. J Allergy Clin Immunol Pract 2014;2:252-257.e1.

10. Sattar HA. Fundamentals of pathology: medical course and step 1 review. Chicago, IL: Pathoma.com, 2017.

11. Yu LC, Perdue MH. Role of mast cells in intestinal mucosal function: studies in models of hypersensitivity and stress. Immunol Rev 2001;179:61-73.

12. Lorentz A, Schwengberg S, Sellge G, Manns MP, Bischoff SC. Human intestinal mast cells are capable of producing different cytokine profiles: role of IgE receptor cross-linking and IL-4. J Immunol 2000;164:43-48.

13. Hamilton MJ, Frei SM, Stevens RL. The multifaceted mast cell in inflammatory bowel disease. Inflamm Bowel Dis 2014;20;2364-2378.

14. Bischoff SC. Physiological and pathophysiological functions of intestinal mast cells. Semin Immunopathol 2009;31:185-205.

15. Boyce JA. Mast cells: beyond IgE. J Allergy Clin Immunol 2003;111:24-32.

16. Ramsay DB, Stephen S, Borum M, et al. Mast cells in gastrointestinal disease. Gastroenterol Hepatol (N Y) 2010;6:772-777.

17. Bischoff SC, Krämer S. Human mast cells, bacteria, and intestinal immunity. Immunol Rev 2007;217:329-337.

18. Abonia JP, Blanchard C, Butz BB, et al. Involvement of mast cells in eosinophilic esophagitis. J Allergy Clin Immunol 2010;126:140-149.

19. Saad AG. Normal quantity and distribution of mast cells and eosinophils in the pediatric colon. Pediatr Dev Pathol 2011;14:294-300.

20. Aich A, Afrin LB, Gupta K. Mast cell-mediated mechanisms of nociception. Int J Mol Sci 2015;16:29069-29092.

21. Neilan NA, Garg UC, Schurman JV, Friesen CA. Intestinal permeability in children/adolescents with functional dyspepsia. BMC Res Notes 2014;7:275.

22. Frieri M, Quershi M. Pediatric mastocytosis: a review of the literature. Pediatr Allergy Immunol Pulmonol 2013;26:175-180.

23. Valent P. Mast cell activation syndromes: definition and classification. Allergy 2013;68:417-424.
24. Valent P, Akin C, Arock M, et al. Definitions, criteria and global classification of mast cell disorders with special reference to mast cell activation syndromes: a consensus proposal. Int Arch Allergy Immunol 2012;157:215-225.

25. O'Shea KM, Aceves SS, Dellon ES, et al. Pathophysiology of eosinophilic esophagitis. Gastroenterology 2018;154:333-345.

26. Wechsler JB, Bryce PJ. Allergic mechanisms in eosinophilic esophagitis. Gastroenterol Clin North Am 2014;43:281-296.

27. Rothenberg ME. Molecular, genetic, and cellular bases for treating eosinophilic esophagitis. Gastroenterology 2015;148:1143-1157.

28. Lomazi EA, Brandalise NA, Servidoni MFPC, Cardoso SR, Meirelles LR. Mast cells distinguish eosinophilic esophagitis in pediatric patients. Arq Gastroenterol 2017;54:192-196.

29. Cianferoni A, Spergel JM, Muir A. Recent advances in the pathological understanding of eosinophilic esophagitis. Expert Rev Gastroenterol Hepatol 2015;9:1501-1510.

30. Friesen CA, Schurman JV, Colombo JM, Abdel-Rahman SM. Eosinophils and mast cells as therapeutic targets in pediatric functional dyspepsia. World J Gastrointest Pharmacol Ther 2013;4:86-96.

31. Schäppi MG, Borrelli $\mathrm{O}$, Knafelz $\mathrm{D}$, et al. Mast cell-nerve interactions in children with functional dyspepsia. J Pediatr Gastroenterol Nutr 2008;47:472-480.

32. Friesen CA, Lin Z, Singh M, et al. Antral inflammatory cells, gastric emptying, and electrogastrography in pediatric functional dyspepsia. Dig Dis Sci 2008;53:2634-2640.

33. Friesen CA, Schurman JV, Qadeer A, Andre L, Welchert E, Cocjin J. Relationship between mucosal eosinophils and anxiety in pediatric dyspepsia. Gastroenterology 2005;129:A-158.

34. Yeom JS, Choi MB, Seo JH, et al. Relationship between headache and mucosal mast cells in pediatric Helicobacter pylori-negative functional dyspepsia. Cephalalgia 2013;33:323-329.

35. Frossi B, Tripodo C, Guarnotta C, et al. Mast cells are associated with the onset and progression of celiac disease. J Allergy Clin Immunol 2017;139:1266-1274.

36. Zhang L, Song J, Hou X. Mast cells and irritable bowel syndrome: from the bench to the bedside. J Neurogastroenterol Motil 2016;22:181-192.

37. Di Nardo G, Barbara G, Cucchiara S, et al. Neuroimmune interactions at different intestinal sites are related to abdominal pain symptoms in children with IBS. Neurogastroenterol Motil 2014;26:196-204.

38. Jakate S, Demeo M, John R, Tobin M, Keshavarzian A. Mastocytic enterocolitis: increased mucosal mast cells in chronic intractable diarrhea. Arch Pathol Lab Med 2006;130:362-367.

39. Lee KN, Lee OY. The role of mast cells in irritable bowel syndrome. Gastroenterol Res Pract 2016;2016:2031480.

40. Sohn W, Lee OY, Lee SP, et al. Mast cell number, substance P and vasoactive intestinal peptide in irritable bowel syndrome with diarrhea. Scand J Gastroenterol 2014;49:43-51.

41. Cheng P, Yao J, Wang C, Zhang L, Kong W. Molecular and cellular mechanisms of tight junction dysfunction in the irritable bowel syndrome. Mol Med Rep 2015;12:3257-3264.

42. Piche T, Saint-Paul MC, Dainese R, et al. Mast cells and cellularity of the colonic mucosa correlated with fatigue and depression in irritable bowel syndrome. Gut 2008;57:468-473.

43. Willot S, Gauthier C, Patey N, Faure C. Nerve growth factor content is increased in the rectal mucosa of children with diarrheapredominant irritable bowel syndrome. Neurogastroenterol Motil 2012;24:734-739, e347.

44. Podolsky DK. Inflammatory bowel disease. $N$ Engl $J$ Med 2002;347:417-429.

45. Nishida Y, Murase K, Isomoto H, et al. Different distribution of mast cells and macrophages in colonic mucosa of patients with collagenous colitis and inflammatory bowel disease. Hepatogastroenterology 2002;49:678-682. 
46. Fox CC, Lazenby AJ, Moore WC, Yardley JH, Bayless TM, Lichtenstein LM. Enhancement of human intestinal mast cell mediator release in active ulcerative colitis. Gastroenterology 1990;99:119-124.

47. Bischoff SC, Lorentz A, Schwengberg S, Weier G, Raab R, Manns MP. Mast cells are an important cellular source of tumour necrosis factor alpha in human intestinal tissue. Gut 1999;44:643-652.

48. Groschwitz KR, Ahrens R, Osterfeld H, et al. Mast cells regulate homeostatic intestinal epithelial migration and barrier function by a chymase/Mcpt4-dependent mechanism. Proc Natl Acad Sci U S A 2009;106:22381-22386.

49. van Hoboken EA, Thijssen AY, Verhaaren R, et al. Symptoms in patients with ulcerative colitis in remission are associated with visceral hypersensitivity and mast cell activity. Scand J Gastroenterol 2011;46:981-987.

50. Santos J, Yang PC, Söderholm JD, Benjamin M, Perdue MH. Role of mast cells in chronic stress induced colonic epithelial barrier dysfunction in the rat. Gut 2001;48:630-636.

51. Noli C, Miolo A. The mast cell in wound healing. Vet Dermatol 2001;12:303-313.

52. Iba Y, Shibata A, Kato M, Masukawa T. Possible involvement of mast cells in collagen remodeling in the late phase of cutaneous wound healing in mice. Int Immunopharmacol 2004;4:1873-1880.

53. Yang Z, Esebua M, Layfield L. The role of mast cells in histologically "normal" appendices following emergency appendectomy in pediatric patients. Ann Diagn Pathol 2016;24:1-3.

54. Amber S, Mathai AM, Naik R, Pai MR, Kumar S, Prasad K. Neuronal hypertrophy and mast cells in histologically negative, clinically diagnosed acute appendicitis: a quantitative immunophenotypical analysis. Indian J Gastroenterol 2010;29:69-73.

55. Singh UR, Malhotra A, Bhatia A. Eosinophils, mast cells, nerves and ganglion cells in appendicitis. Indian J Surg 2008;70:231-234.

56. Karakuş E, Azili MN, Karabulut B, et al. Is there a role of interstitial cells of cajal and mast cells and eosinophils in appendicitis in children? Turk J Med Sci 2015;45:800-803.

57. Kapur RP. Practical pathology and genetics of Hirschsprung's disease. Semin Pediatr Surg 2009;18:212-223.

58. Kobayashi H, Yamataka A, Fujimoto T, Lane GJ, Miyano T. Mast cells and gut nerve development: implications for Hirschsprung's disease and intestinal neuronal dysplasia. J Pediatr Surg 1999;34:543-548.

59. Szylberg L, Marszałek A. Diagnosis of Hirschsprung's disease with particular emphasis on histopathology. A systematic review of current literature. Prz Gastroenterol 2014;9:264-269.

60. Demirbilek S, Ozardali HI, Aydm G. Mast-cells distribution and colonic mucin composition in Hirschsprung's disease and intestinal neuronal dysplasia. Pediatr Surg Int 2001;17:136-139.

61. Hermanowicz A, Debek W, Dzienis-Koronkiewicz E, Chyczewski L. Topography and morphometry of intestinal mast cells in children with Hirschsprung's disease. Folia Histochem Cytobiol 2008;46:65-68.

62. Yadav AK, Mishra K, Mohta A, Agarwal S. Hirschsprung's disease: is there a relationship between mast cells and nerve fibers? World J Gastroenterol 2009;15:1493-1498.

63. Michelet M, Schluckebier D, Petit LM, Caubet JC. Food proteininduced enterocolitis syndrome - a review of the literature with focus on clinical management. J Asthma Allergy 2017;10:197-207.

64. Ishige T, Yagi $\mathrm{H}$, Tatsuki $\mathrm{M}$, et al. Endoscopic findings in the acute phase of food protein-induced enterocolitis syndrome. Pediatr Allergy Immunol 2015;26:90-91.

65. Caubet JC, Bencharitiwong R, Ross A, Sampson HA, Berin MC, Nowak-Węgrzyn A. Humoral and cellular responses to casein in patients with food protein-induced enterocolitis to cow's milk. J Allergy Clin Immunol 2017;139:572-583.

66. Lee MJ, Akin C. Mast cell activation syndromes. Ann Allergy Asthma Immunol 2013;111:5-8.

67. Akin C, Valent P, Metcalfe DD. Mast cell activation syndrome: Proposed diagnostic criteria. J Allergy Clin Immunol 2010;126: 1099-1104.e4.

68. Picard M, Giavina-Bianchi P, Mezzano V, Castells M. Expanding spectrum of mast cell activation disorders: monoclonal and idiopathic mast cell activation syndromes. Clin Ther 2013;35:548-562.

69. Akin C. Mast cell activation syndromes. J Allergy Clin Immunol 2017;140:349-355.

70. Akin C, Valent P. Diagnostic criteria and classification of mastocytosis in 2014. Immunol Allergy Clin North Am 2014;34:207-218.

71. Méni C, Bruneau J, Georgin-Lavialle S, et al. Paediatric mastocytosis: a systematic review of 1747 cases. Br J Dermatol 2015;172:642-651.

72. Carter MC, Clayton ST, Komarow HD, et al. Assessment of clinical findings, tryptase levels, and bone marrow histopathology in the management of pediatric mastocytosis. J Allergy Clin Immunol 2015;136:1673-1679.

73. Frieri M. Mast cell activation syndrome. Clin Rev Allergy Immunol 2018;54:353-365. 